\title{
Study on Preparation and Properties of Enamel Material
}

\author{
Shenhai Wang, Junhao Zhang \\ Zaozhuang Vocational College of Science and Technology, Zaozhuang, Shandong, China
}

\begin{abstract}
Reference to the domestic and foreign relevant technical data, the paper design and manufacture enamel materials with a temperature resistant shock resistance and acid resistance excellent chemical stability, research on microscopic morphology of the enamel surface by scanning electron microscope, the experiment results showed: mill addition certain amount of zirconium silicate crystal in enamel material, enable enamel material to form composite materials of amorphous material and zirconium silicate crystals, it can effectively improve its temperature shock property; it is necessary to improve the enamel material temperature resistance shock property, but also maintain its excellent acid resistance, there is a optimal weight range mill addition into zirconium silicate crystal.
\end{abstract}

Keyword-one-coat enamel; adherence; acid resistance; interface; resistance to thermal shock.

\section{INSTRUCTION}

Enamel is one or more layers of glass glaze that deep overbite in the metal surface, composite solid combination that metal and inorganic oxides firing at high temperature. Enamel coating is a kind of amorphous inorganic nonmetallic materials, the surface is smooth, with good corrosion resistance. It has the strength of steel, extensibility and glass acid and alkali corrosion resistance, not easy to contaminate the products, easy cleaning and other advantages, it can give the material surface abrasion resistance, corrosion resistance, heat resistance, radiation resistance, and optical, electric, thermal, magnetic and other special performance, so as to improve the performance, extended to the service life.

This paper systematically developed enamel formula, prepared enamel good acid resistance, and zirconium silicate crystal is introduced into the enamel by mill addition method, the preparation of composite enamel materials not only excellent acid resistance, and high temperature resistant blast performance is also very good, fully able to meet the requirements of desulfurization of heat exchanger heat exchange plate technology. The paper analyze the enamel materials uses scanning electron microscope morphology, and research on the effect of surface structure of the enamel materials on enamel material performance.

\section{ENAMEL GLAZE PREPARATION}

Enamel glaze must possess excellent acidproof chemical stability. According to the related research information analysis showed that the enamel, introduce $\mathrm{SiO} 2$ and $\mathrm{TiO} 2$ can improve the acid resistance of enamel glaze; at the same time, the introduction of $\mathrm{Li2O}$, the enamel $\mathrm{Na} 2 \mathrm{O}$, K2O, have a "double base effect" or "multi alkali effect" is conducive to the improvement of acid resistance of enamel and reduced enamel sintering temperature; the introduction of B2O makes the firing enamel on bottom slab infiltration capacity enhancement; at the same time, the introduction of $\mathrm{CoO}$, the enamel $\mathrm{NiO}$, Sb2O, MoO3, to form composite adherence agent, can effectively promote the enamel layer and metal iron adherence strength [1-3]. Comprehensively considering the influence of all kinds of enamel oxide on the physical and chemical properties, the design and preparation of acid has excellent chemical stability enamel chemical composition range, as shown in tab.1.

According to tab.1 acid composition range excellent chemical stability of chemical composition of enamel glaze, enamel glaze batch melt temperature in $(1350+50){ }^{\circ} \mathrm{C}$, melting $(120+5) \mathrm{min}$, and then take the enamel melt into the water quench, get the enamel frit. Then the enamel frit and mill addition ratio in Tab.2 (mass fraction) were mixed and ball milling.

Enamel milled become glaze slurry, remove excessive enamel frit coarse particles after 120 standard sieve.

TABLE. I. CHEMICAL COMPOSITION RANGE OF ENAMEL WITH GOOD ACID RESISTANCE

\begin{tabular}{cc}
\hline Chemical composition & Mass fraction $\%$ \\
\hline $\mathrm{SiO}_{2}+\mathrm{TiO}_{2}$ & $50.0 \sim 70.0$ \\
$\mathrm{~B}_{2} \mathrm{O}_{3}+\mathrm{Al}_{2} \mathrm{O}_{3}$ & $5.0 \sim 12.0$ \\
$\mathrm{Na}_{2} \mathrm{O}+\mathrm{K}_{2} \mathrm{O}+\mathrm{Li}_{2} \mathrm{O}$ & $8.0 \sim 16.0$ \\
$\mathrm{CaO}+\mathrm{MgO}+\mathrm{BaO}$ & $2.0 \sim 8.0$ \\
$\mathrm{Na}_{2} \mathrm{SiF}_{6}+\mathrm{CaF}_{2}$ & $2.0 \sim 5.0$ \\
$\mathrm{Sb}_{2} \mathrm{O}_{3}+\mathrm{MoO}_{3}$ & $1.0 \sim 5.0$ \\
$\mathrm{CoO}+\mathrm{NiO}$ & $1.0 \sim 2.5$ \\
$\mathrm{FeO}+\mathrm{CuO}$ & $0.5 \sim 1.5$ \\
\hline
\end{tabular}

TABLE. II. ENAMEL FRIT AND MILL ADDITIONS

\begin{tabular}{cccccc}
\hline Frit & Clay & Sodium nitrite & Borax & Water & $\begin{array}{c}\text { Zirconium } \\
\text { silicate }\end{array}$ \\
\hline $100 \%$ & $5.5 \%$ & $0.2 \%$ & $0.2 \%$ & $45 \%$ & $0 \sim 30 \%$ \\
\hline
\end{tabular}

\section{PERFORMANCE TEST}

\section{A. Enamel adherence performance testing}

Enamel adherence performance determine to the strength of adherence level. The adherence intensity is one 
of the important technical index of enamel material, it reflects the enamel layer and metal iron layer combined with the level of quality. Enamel is a composed of metallic iron layer and inorganic enamel glaze layer composite, direct measurement of adherence strength enamel is very difficult, the test method of enamel adherence strength of enamel workers have carried out extensive and in-depth research, in the existing test methods, almost all used indirect method to test the strength of adherence enamel the comparison of test methods are commonly used, falling ball impact, extrusion, salt solution method etc..

The paper adopts the most commonly used method of falling ball impact test, the adherence intensity of enamel glaze layer and metal iron layer. According to the test standard of European enamel, testing standard EN 10209enamel adherence strength, since the height of 750 free fall with a $1.5 \mathrm{~kg}$ ball, the impact model of surface enamel, enamel material surface fall porcelain status was observed after the impact, so as to judge the strength of adherence enamel material.

According to the test standard of European enamel ((EN10209), the adherence intensity of enamel can be divided into five levels, the best level 1, level 5 is the worst. Adherence test standard graph as shown in fig.1.
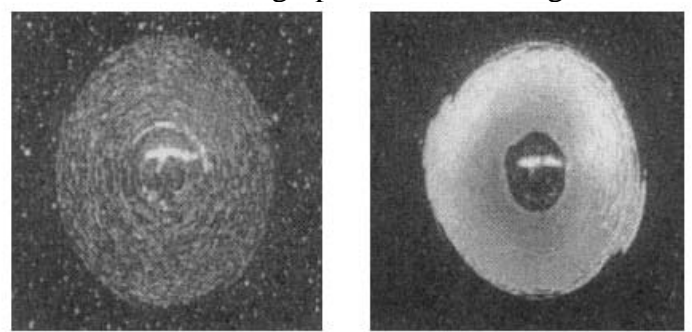

(a) 1 level adherence strength (b) 5 level adherence strength

Figure 1. Standard test chart

The experimental results are introduced: Ti02 less, it has good enamel adherence, Ti02 partial substitution of Si02 content is excessive, enamel adherence become significantly worse. Small amounts of Ti02 instead of Si02, content of titanium is $2-4 \mathrm{wt} \%$, the adherence intensity of enamel material is 1 levels, the most ideal for adherence.

\section{B. High temperature blast performance test}

In accordance with the national standard GB 114191989 "heat resistance test method" to detect performed on the enamel material temperature resistance shock property, detection procedure is the enamel model tested into $200^{\circ} \mathrm{C}$ electric stove in $10 \mathrm{~min}$ and then removing, put in $4^{\circ} \mathrm{C}$ water quench, observe the enamel material surface is damaged, if the surface is in good condition enamel material, no crack, no change, then the temperature resistant blast performance testing through; then drying, and then the electric furnace temperature raised to $20^{\circ} \mathrm{C}$, continue to repeat the test, damaging the surface until the enamel materials so far. Test temperature before damage to the enamel material temperature resistance temperature blast.
Fig. 2 is the amount of zirconium silicate mill addition (mass fraction) relationship with enamel material temperature blast performance. We can see from Fig.2, with the increase of mill amount of zirconium silicate addition, resistance temperature blast enamel material increases rapidly; when the zirconium silicate mill addition reached 1000 (mass fraction), the enamel material temperature resistance blast performance increase gradually stabilized; when the zirconium silicate mill addition reached 2000 (mass fraction), the enamel material temperature resistance performance is basically not increasing blast.

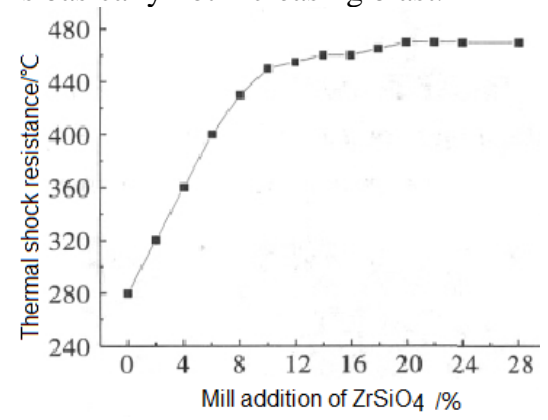

Figure 2. Relation between mill addition of $\mathrm{ZrSiO} 4$ and thermal shock resistance of the enamel

\section{Acid resistance tests}

According to international standard IS02743-73 "enamel to boiling hydrochloric acid erosion performance determination" to detect the chemical stability of enamel material acid, detection procedure is the tested enamel model into $30 \%$ (mass fraction) $\mathrm{H} 2 \mathrm{SO} 4$ solution in $18 \mathrm{~h}$ boiling, and then the quality detection of changes before and after the enamel material testing, in order to determine the acid the chemical stability of the enamel material. Because the heat transfer plate is device for desulfurization, so will change into sulfuric acid hydrochloric acid standard.

Enamel material and acid erosion amount and acid resistance is inversely proportional to the relationship, fig.2 is the amount of zirconium silicate mill addition (mass fraction) relationship with enamel material acid erosion. From Fig.3 shows, with the increase of addition amount of zirconium silicate mill, acid erosion of enamel material gradually increase the chemical stability, acid decreased gradually, when the zirconium silicate mill addition amount is $12 \%$ (mass fraction) the following, the sulfate erosion amount is less than $2 \mathrm{~g} / \mathrm{m} 2$, still meet the national standard requirements; when the zirconium silicate mill addition reached $16 \%$ (mass fraction), the acid erosion of enamel material and further increase the chemical stability, acid also further reduce sulfate, the erosion amount is greater than $2 \mathrm{~g} / \mathrm{m} 2$, has exceeded the national standard requirements; when the zirconium silicate mill addition reached to $25 \%$ (mass fraction) above, acid erosion of enamel material increases rapidly, then acid chemistry stability is also greatly reduced, the sulfate erosion is greater than $3 \mathrm{~g} / \mathrm{m} 2$ 


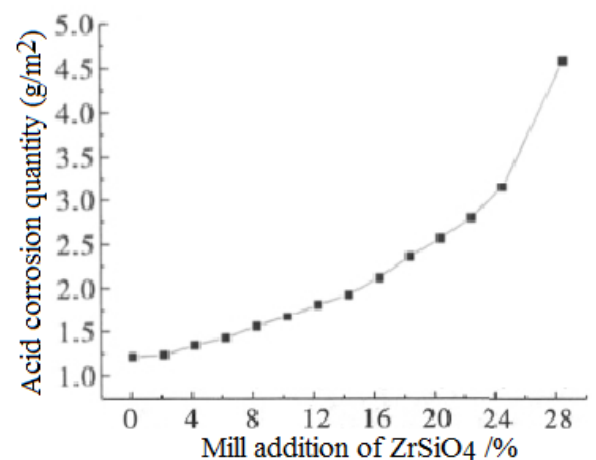

Figure 3. Relation between mill addition of $\mathrm{ZrSiO} 4$ and acid corrosion quantity of the enamel

\section{Analysis of surface microstructure}

Ultrasonic clean enamel surface, analysis of micro morphology of enamel samples using QUANTA-200F scanning electron microscope.

Fig.3 (a) is a microscopic morphology of no mill addition zirconium silicate enamel surface, we can be found that the enamel surface structure without mill addition zirconium silicate is very compact; Fig.3 (b) is mill addition $10 \%$ (mass fraction) microstructure, zirconium silicate enamel surface can be found, mill addition $10 \%$ (mass fraction) there are some white spots the enamel surface of zircon, zirconium silicate particles, at the enamel surface structure is relatively compact; Fig.3 (c) is mill addition25\% (mass fraction) microstructure, zirconium silicate enamel surface can be found, mill addition $25 \%$ (mass fraction) there are many white enamel surface of zirconium silicate, these white spots have been the destruction of the surface enamel structure compact, relatively rough surface and there are some small pores, reflected in the macro performance, acid erosion greatly increases the chemical stability of the surface enamel, enamel decreased significantly (see Fig.4).

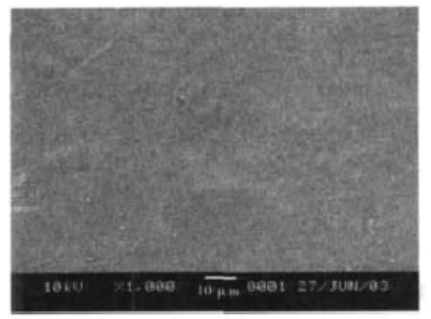

(a) $0 \% \mathrm{ZrSiO} 4$

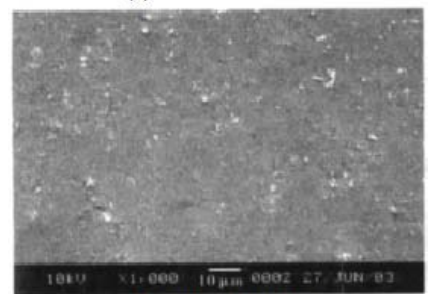

(b) $10 \% \mathrm{ZrSiO} 4$

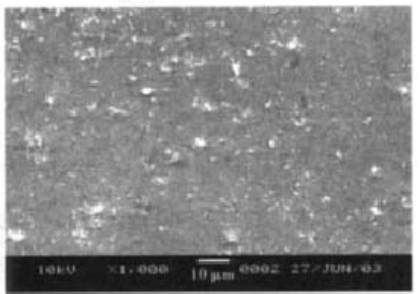

(c) $25 \% \mathrm{ZrSiO} 4$

Figure 4. 1Microstructure of the enamel surface

\section{CONCLUSIONS}

(1) In enamel material, mill addition certain amount of zirconium silicate crystal to enamel material, which enable enamel material form composite materials of amorphous material and zirconium silicate crystals that can effectively improve its temperature shock property.

(2) It is necessary to improve the enamel material temperature resistance shock property, but also to maintain its excellent acid resistance, there is an optimal weight range $(10 \%-12 \%$ (mass fraction)) of zirconium silicate crystal mill addition.

\section{REFERENCES}

[1] Wang Yueqing. Flue gas desulfurization dust integration device and its application in coal-fired boiler [J]. Energy research and information, 2000, 16 (2): 35

[2] Jinbiao Lu, and so on. China enamel Handbook [M]. Beijing: Chinese Light Industry Press, 2001

[3] Gu Weiqiang, Li Jingxue, Qian Huichun, etc.. A lining acidproof enamel interface transition layer of structure [J]. Glass and enamel.2011, 39 (2): 7

[4] Li Jingxue, Qian Huichun, Jiang Weizhong. Study on a low temperature enamel cast iron enamel [J]. Glass and enamel 2011, 39 (1): 6 